\title{
Ir-Catalyzed Reduction of Carbonyl Compounds Using Biogenetic Alcohols
}

\author{
Yuta Nishina ${ }^{1,2}$ (D) \\ 1 Research Core for Interdisciplinary Sciences, Okayama University, Okayama 700-8530, Japan; \\ nisina-y@cc.okayama-u.ac.jp; Tel.: +81-86-251-8718 \\ 2 Graduate School of Natural Science and Technology, Okayama University, Okayama 700-8530, Japan
}

Received: 6 May 2019; Accepted: 2 September 2019; Published: 12 September 2019

\begin{abstract}
Biomass has gained great attention as an alternative to fuel-derived chemicals. This report concerns new catalytic systems consisting of $\left[\mathrm{IrCp}^{*} \mathrm{Cl}_{2}\right]_{2}\left(\mathrm{Cp}^{*}\right.$ : Pentamethylcyclopentadienyl) for the reduction of aldehyde and biogenetic alcohols as hydrogen sources. $\left[\operatorname{IrCp}{ }^{*} \mathrm{Cl}_{2}\right]_{2}$ has been used as a transfer hydrogenation catalyst using fossil fuel-derived alcohols as hydrogen sources in the presence of a base. In contrast, our system does not require any base, and the reaction can proceed in water. Various types of biogenetic alcohols can be used as hydrogen sources, such as monosaccharides, oligosaccharides, and glycerol. Aromatic and aliphatic aldehydes, as well as ketones, were successfully reduced to the corresponding alcohols in the present system.
\end{abstract}

Keywords: iridium; aldehyde; ketone; sugar; glycerol; biogenetic; biomass; reduction; hydrogenation; hydrogen transfer

\section{Introduction}

Fossil fuels play a dominant role in chemical sciences and industries. However, fossil fuel dependency is unsustainable due to its limited amount of resources. Moreover, a large number of greenhouse gases, such as $\mathrm{CO}_{2}$, are emitted by the use of fossil fuels. Biomass has the potential to provide a sustainable and carbon-neutral process which complements the drawback of fossil fuels and possibly suppresses global warming [1]. In recent years, a number of research directions focusing on biomass transformation have been explored, such as for biofuels and bioplastics [2]. On the other hand, a trivalent iridium complex bearing a pentamethylcyclopentadienyl $\left(\mathrm{Cp}^{*}\right)$ ligand is a well-known stable complex [3]. The C $\mathrm{p}^{*}$ ligand is not susceptible to chemical transformation and has been used as an effective ligand because it can form stable coordination with a metal center in a tridentate coordination fashion. Thus, the $\mathrm{Cp}^{*}$ ligand has been employed to improve the stabilities and hemilabilities of catalytically active species [4]. Therefore, a number of $\operatorname{IrC} \mathrm{p}^{*}$-catalyzed reactions have been reported so far [5]; however, there has been no report on the reduction of carbonyl compounds using biogenetic alcohols as hydrogen sources despite the known reducing property of glucose in the field of metal nanoparticles synthesis [6]. Though RhCp*-catalyzed hydrogenation using sugars as hydrogen sources has been reported, excess amounts of sugar, bases, and toxic chlorinated solvents were necessary [7]. Herein, [ $\left.\mathrm{IrCp}^{*} \mathrm{Cl}_{2}\right]_{2}$-catalyzed reduction of carbonyl groups is reported, which consists of biogenetic alcohols, such as monosaccharides, oligosaccharides, or glycerol, as a hydrogen source. This system does not require any base, and the reaction can proceed in the presence of water.

\section{Results and Discussions}

The investigation on the optimization of $\left[\mathrm{IrCp}^{*} \mathrm{Cl}_{2}\right]_{2}$-catalyzed reaction condition using 2naphthaldehyde (1a) as a substrate was performed. Reductions of $\mathbf{1 a}$ using sugars as hydrogen sources under base-free conditions were conducted. The reaction was carried out using different types of solvents in 
the presence of $\left[\mathrm{IrCp}{ }^{*} \mathrm{Cl}_{2}\right]_{2}$ as a catalyst (5.0 mol \%-Ir) and glucose as a hydrogen source at $85^{\circ} \mathrm{C}$ for $24 \mathrm{~h}$; as a result, 2-naphthyl methanol (2a) was formed (Table 1). In order to dissolve glucose, water was required for this reaction. The choice of solvent was essential for the high conversion of 1a; a less polar solvent such as $\mathrm{CH}_{2} \mathrm{Cl}_{2}$ and toluene showed lower yields of $45 \%$ (Entry 1) and 61\% (Entry 2), while a polar solvent such as tetrahydrofuran (THF), MeOH, and 1,4-dioxane gave higher yields of 81\% (Entry 3), 93\% (Entry 4) and 95\% (Entry 5), respectively. When the amount of the catalyst was reduced to $1 \mathrm{~mol} \%$, the product yield decreased to $53 \%$ (Entry 6). The addition of a base may have had some effect; the product yield slightly increased to $60 \%$ when $1 \mathrm{~mol} \%$ of $\mathrm{Ir}$ and $10 \mathrm{~mol} \%$ of $\mathrm{K}_{2} \mathrm{CO}_{3}$ were used (Entry 7).

Table 1. Optimization of solvents in the reduction of $1 \mathbf{a}^{\mathrm{a}}$.

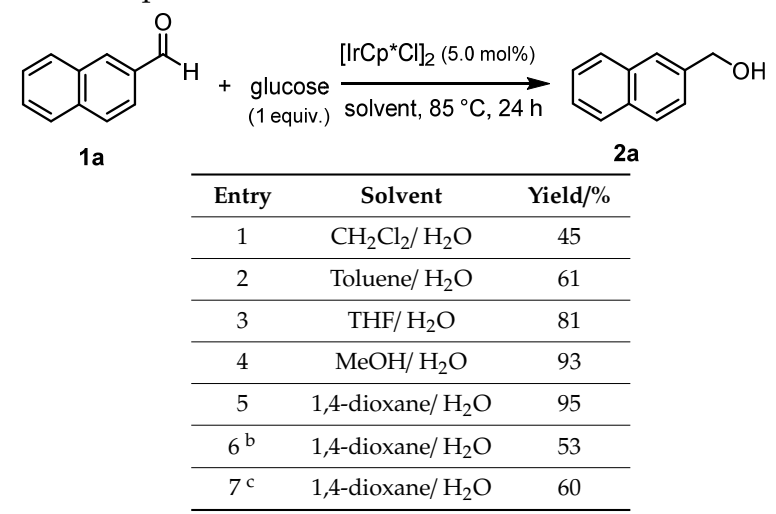

\footnotetext{
a The reaction was carried out with benzaldehyde $(0.25 \mathrm{mmol})$, glucose $(0.25 \mathrm{mmol})$ and $\left[\mathrm{IrCp}^{*} \mathrm{Cl}_{2}\right]_{2}(0.0125 \mathrm{mmol}$, $5.0 \mathrm{~mol} \%)$ in a solvent $\left(1 \mathrm{~mL}, 1: 1\right.$ with water) at $85^{\circ} \mathrm{C}$ for $24 \mathrm{~h}$. Yields were determined by ${ }^{1} \mathrm{H}$ NMR using 1,1,2,2-tetrachloroethane as an internal standard. ${ }^{b}\left[\mathrm{IrCp}^{*} \mathrm{Cl}_{2}\right]_{2}(0.0025 \mathrm{mmol}, 1.0 \mathrm{~mol} \%)$ was used. ${ }^{\mathrm{c}}\left[\mathrm{IrCp}^{*} \mathrm{Cl}_{2}\right]_{2}$ $(0.0025 \mathrm{mmol}, 1.0 \mathrm{~mol} \%)$ and $\mathrm{K}_{2} \mathrm{CO}_{3}(10 \mathrm{~mol} \%)$ was used.
}

Encouraged by the above results, we envisaged using other sugars in the $\operatorname{IrC} \mathrm{p}^{*}$-catalyzed reactions. The results of the investigation are summarized in Table 2. The reaction of monosaccharides, such as glucose, galactose, and xylose, resulted in excellent yields (Entries 1-3). When the reaction was performed using a disaccharide such as lactose, sucrose, and maltose, similar yields were obtained (Entries 4-6), while decreasing the amount of disaccharide also caused a decrease of the product yield. This suggests a 1:1 reaction of a sugar and 1a despite of the number of hydroxyl groups (Entry 7). Similarly, trisaccharide, and raffinose also gave $\mathbf{2 a}$ in a high yield (Entry 8). However, when cellulose was used, the reaction did not proceed. These results suggest that the choice of sugar is also essential.

Table 2. Reduction of 1 a using various sugars as hydrogen sources ${ }^{a}$.

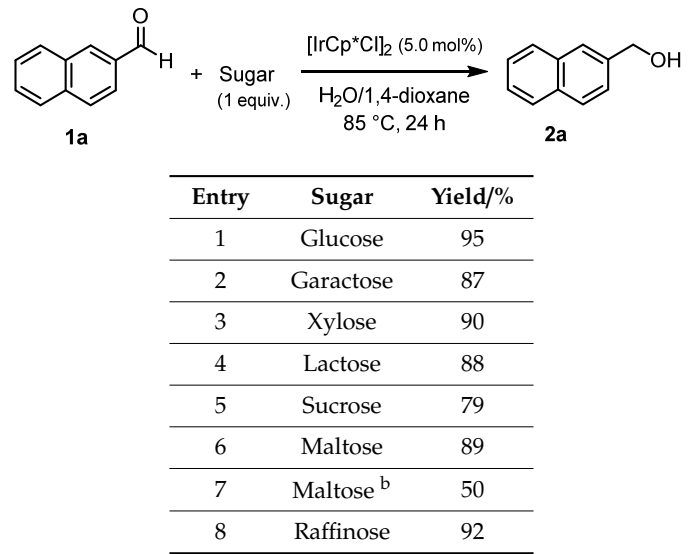

a The reaction was carried out with $1 \mathrm{a}(0.25 \mathrm{mmol})$, sugar $(0.25 \mathrm{mmol})$ and $\left[\operatorname{IrCp} \mathrm{Cp}^{*} \mathrm{Cl}_{2}\right]_{2}(0.0125 \mathrm{mmol}, 5.0 \mathrm{~mol} \%)$ in $\mathrm{H}_{2} \mathrm{O}$ $(0.5 \mathrm{~mL})$ and 1.4-dioxane $(0.5 \mathrm{~mL})$ at $85^{\circ} \mathrm{C}$ for $24 \mathrm{~h}$. Yields were determined by NMR using 1,1,2,2-tetrachloroethane as an internal standard. ${ }^{\mathrm{b}}$ Sugar $(0.12 \mathrm{mmol})$ was used. 
Next, the reduction reactions of various aldehydes were investigated (Table 3). As described above, 1a gave $\mathbf{2 a}$ in an $88 \%$ isolated yield (Entry 1). Noticeable electronic and steric effects were not observed for aromatic aldehydes bearing the 4-methyl (1b, Entry 2), 4-cyano (1c, Entry 3), 4-trifluoromethyl (1d, Entry 4), 4-bromo (1e, Entry 5), and 2-bromo groups (1f, Entry 6). Heteroaromatic aldehydes, such as 4-pyridinecarboxaldehyde (1g, Entry 7) and 2-thiophenecarboxaldehyde (1h, Entry 8) were converted to the corresponding alcohols. Furthermore, alkyl aldehyde (1i, Entry 9) and ketone (1j, Entry 10) could also be applicable. However, any alkenes and alkynes were out of the scope for the catalytic system.

Table 3. IrCp*-catalyzed reduction of various carbonyl compounds using glucose as a hydrogen source ${ }^{\text {a }}$.

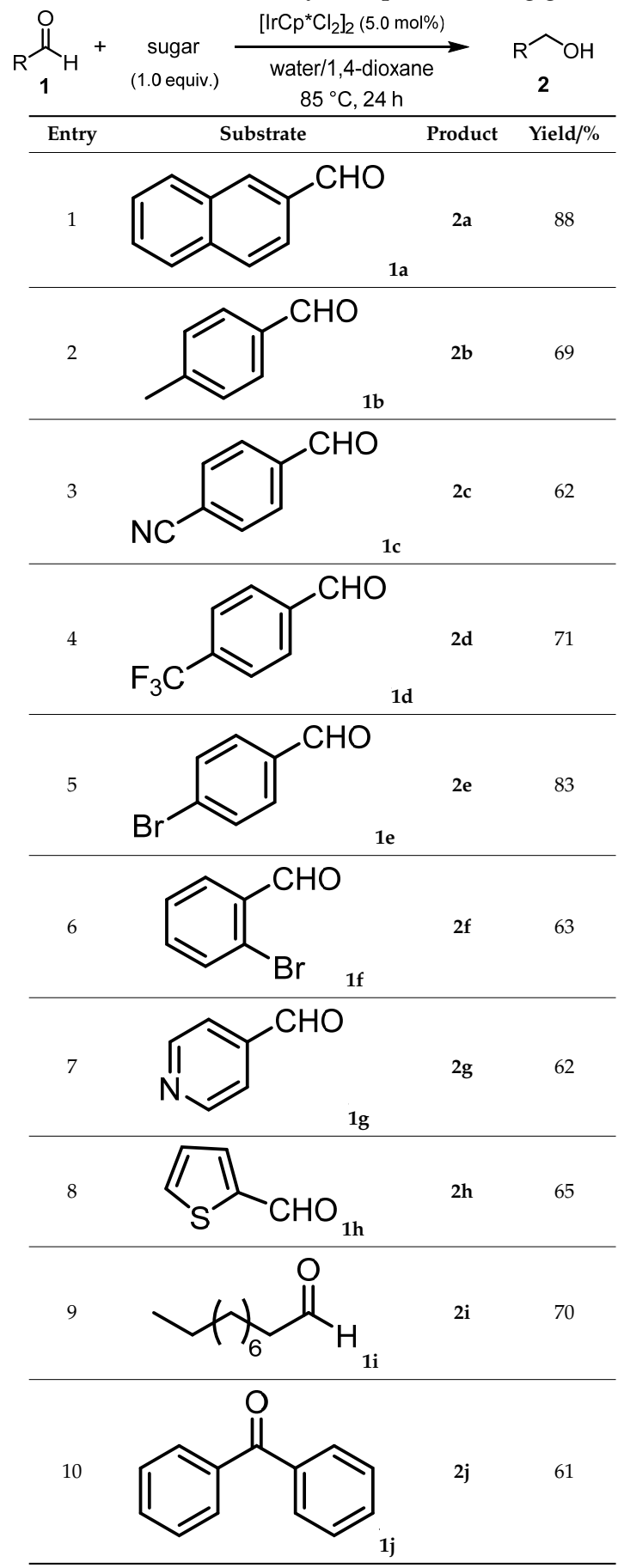

a The reaction was carried out with $1(0.25 \mathrm{mmol})$, glucose $(0.25 \mathrm{mmol})$ and $\left[\mathrm{IrCpCl}_{2}\right]_{2}(0.0125 \mathrm{mmol}, 5.0 \mathrm{~mol}$ $\%)$ in $\mathrm{H}_{2} \mathrm{O}(0.5 \mathrm{~mL})$ and 1.4-dioxane $(0.5 \mathrm{~mL})$ at $85{ }^{\circ} \mathrm{C}$ for $24 \mathrm{~h}$. Yields were determined after isolation with column chromatography. 
A time-resolved reaction profile for the $\left[\mathrm{IrCp}^{*} \mathrm{Cl}_{2}\right]_{2}$-catalyzed reduction of aldehyde 1 a to alcohol 2a is shown in Figure 1. This profile indicates that the 2a product gradually formed, and a $24 \mathrm{~h}$ reaction is necessary.

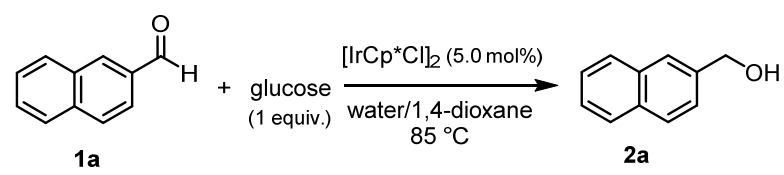

1a

2a

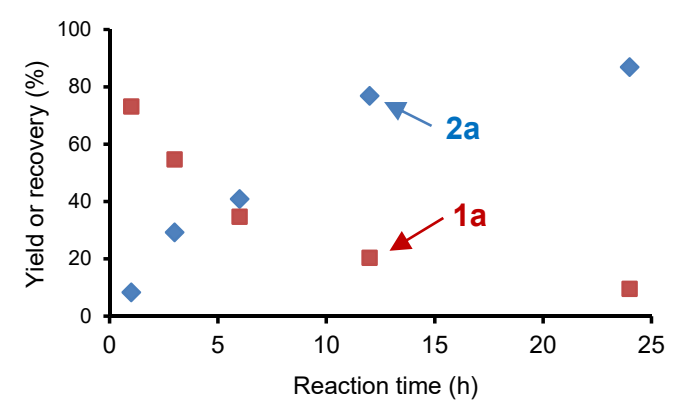

Figure 1. Time-course analysis of the product yield of $\mathbf{2 a}$ or recovery of $\mathbf{1 a}$. The reaction was carried out with $1 \mathrm{a}(0.25 \mathrm{mmol})$, glucose $(0.25 \mathrm{mmol})$, and $\left[\mathrm{IrCp}^{*} \mathrm{Cl}_{2}\right]_{2}(0.0125 \mathrm{mmol}, 5.0 \mathrm{~mol} \%)$ in $\mathrm{H}_{2} \mathrm{O}(0.5 \mathrm{~mL})$ and 1.4-dioxane $(0.5 \mathrm{~mL})$ at $85^{\circ} \mathrm{C}$. Product yields were determined by gas chromatography using dodecane as an international standard.

Next, an investigation was performed to confirm which hydrogen on a sugar was used as a reductant. Using methyl $\alpha$-D glucoside, the system did not afford the desired product (Table 4, Entry 1). However, another biogenetic alcohol, glycerol, worked as a hydrogen source (Table 4, Entry 2). This suggests that glucose binds to the Ir center via the deprotonated hydroxyl group at the anomeric carbon followed by a hydrogen shift from that carbon to iridium, and then the reduction of the aldehyde may occur.

Table 4. Investigation of hydrogen source ${ }^{\mathrm{a}}$.

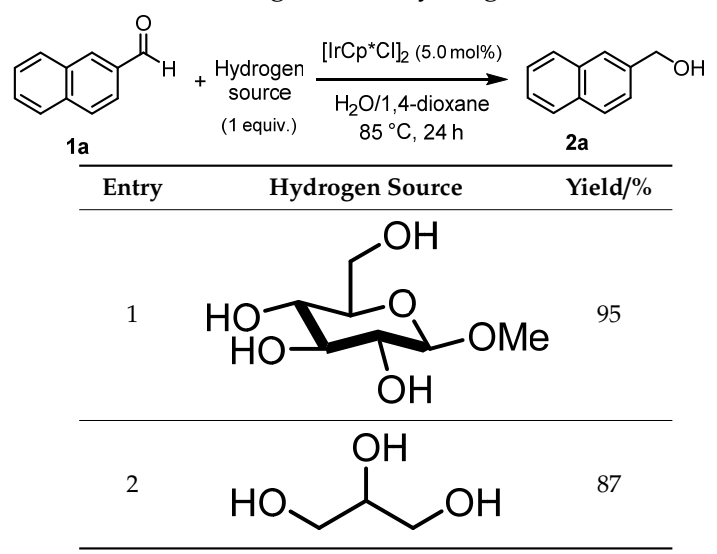

\footnotetext{
a The reaction was carried out with $1 \mathrm{a}(0.25 \mathrm{mmol})$, hydrogen source $(0.25 \mathrm{mmol})$ and $\left[\mathrm{IrCp}^{*} \mathrm{Cl}_{2}\right]_{2}(0.0125 \mathrm{mmol}$, $5.0 \mathrm{~mol} \%)$ in $\mathrm{H}_{2} \mathrm{O}(0.5 \mathrm{~mL})$ and 1.4-dioxane $(0.5 \mathrm{~mL})$ at $85^{\circ} \mathrm{C}$ for $24 \mathrm{~h}$. Yields were determined by isolation with column chromatography.
}

The reaction mechanism is supposed to be similar to the traditional $\left[\mathrm{IrCp}^{*} \mathrm{Cl}_{2}\right]_{2}$-catalyzed transfer hydrogenation with fossil fuel-derived alcohols [3]. However, the reason for the lack of need of the base is still unclear. Further investigations would be necessary to distinguish the difference among the reaction mechanisms occurring with different types of alcohol. 


\section{Materials and Methods}

All reactions were carried out under an argon atmosphere. 1,4-dioxane and $\mathrm{D}(+)$-glucose were purchased from Wako Pure Chemical Industries (Osaka, Japan). The Ir complex was purchased from Furuya Metal Co., Ltd. (Tokyo, Japan). Glucono- $\delta$-lactone was purchased from Kishida Chemical Co. (city, country), which was used for the LC-MS analysis of the standard sample. ${ }^{1} \mathrm{H}(400 \mathrm{MHz})$ and ${ }^{13} \mathrm{C}(100 \mathrm{MHz})$ NMR spectra were recorded using a JEOL JNM-LA400 spectrometer (JEOL, Ltd, Tokyo, Japan). Proton chemical shifts were relative to solvent peaks [chloroform: $7.27\left({ }^{1} \mathrm{H}\right), 77.00\left({ }^{13} \mathrm{C}\right)$ ]. Reactions were monitored by thin-layer chromatography (TLC) that was carried out on $0.25 \mathrm{~mm}$ Merck silica gel plates 60F-254 (Merck, Darmstadt, Germany) using UV light for visualization.

The catalytic reaction was performed as follows: Aldehyde $(0.25 \mathrm{mmol})$, sugar $(0.25 \mathrm{mmol})$ and $\left[\mathrm{IrCp}^{*} \mathrm{Cl}_{2}\right]_{2}(5.0 \mathrm{~mol} \%)$ were dissolved in $\mathrm{H}_{2} \mathrm{O}(0.5 \mathrm{~mL})$ and 1,4-dioxane $(0.5 \mathrm{~mL})$. The reaction mixture was stirred for $24 \mathrm{~h}$ at $85^{\circ} \mathrm{C}$. After cooling, the reaction mixture was diluted with $\mathrm{H}_{2} \mathrm{O}$ and extracted with ethyl acetate. For gas chromatography analysis, a known amount of dodecane was added in the mixture, and the product yield was determined by comparing the areas of the GC spectra. For ${ }^{1} \mathrm{H}$ NMR analysis, the mixture was concentrated under reduced pressure, and the crude ${ }^{1} \mathrm{H}-\mathrm{NMR}$ spectra in $\mathrm{CDCl}_{3}$ was obtained using a known amount of 1,1,2,2-tetrachloroethane as an internal standard (see Supplementary Materials). The yield was measured by integrating the $\mathrm{H}$ of the benzylic position with respect to the 1,1,2,2-tetrachloroethane peak.

\section{Conclusions}

The $\left[\mathrm{IrCp}{ }^{*} \mathrm{Cl}_{2}\right]_{2}$-catalyzed reduction of carbonyl compounds was achieved using biogenetic alcohols, such as sugars and glycerol. The mechanism of the reaction was similar to the previously developed hydrogen transfer reactions using alcohols as hydrogen sources [3]; however, the developed system herein does not require the addition of a base. The utilization of biogenetic alcohols as hydrogen sources will provide new methods for organic synthetic chemistry and will contribute to the fields of sustainable chemical engineering research. Currently, a long reaction time of $24 \mathrm{~h}$ is required, but this could be improved by modifying the structure of the ligand on $\operatorname{Ir}[8]$ and will be investigated in the future work.

Supplementary Materials: The following are available online at http://www.mdpi.com/2304-6740/7/9/114/s1. NMR data and ESI-MS data.

Funding: This research received funding from CHUSEI KOGYO CO., LTD.

Acknowledgments: This research was supported by Tatsuya Kida and Tomonari Ureshino.

Conflicts of Interest: The authors declare no conflict of interest.

\section{References}

1. Corma, A.; Iborra, S.; Velty, A. Chemical Routes for the Transformation of Biomass into Chemicals. Chem. Rev. 2007, 107, 2411-2502. [CrossRef] [PubMed]

2. Romain-Leshkov, Y.; Barrett, C.J.; Liu, Z.Y.; Dumesic, J.A. Production of dimethylfuran for liquid fuels from biomass-derived carbohydrates. Nature 2007, 447, 982. [CrossRef] [PubMed]

3. Fujita, K.; Furukawa, S.; Yamaguchi, R. Oxidation of primary and secondary alcohols catalyzed by a pentamethylcyclopentadienyliridium complex. J. Organomet. Chem. 2002, 649, 289-292. [CrossRef]

4. Kang, J.W.; Moseley, K.; Maitlis, P.M. Pentamethylcyclopentadienylrhodium and-iridium halides. I. Synthesis and properties. J. Am. Chem. 1969, 91, 5970-5977. [CrossRef]

5. Fujita, K.; Yamaguchi, R. Cp*Ir complex-catalyzed hydrogen transfer reactions directed toward environmentally benign organic synthesis. Synlett 2005, 4, 560-571. [CrossRef]

6. Engelbrekt, C.; Sørensen, K.H.; Zhang, J.; Welinder, A.C.; Jensen, P.S.; Ulstrup, J. Green synthesis of gold nanoparticles with starch-glucose and application in bioelectrochemistry. J. Mater. Chem. 2009, 19, 7839-7847. [CrossRef] 
7. Manna, S.; Antonchick, A.P. Catalytic Transfer Hydrogenation Using Biomass as Hydrogen Source. ChemSusChem 2018. [CrossRef] [PubMed]

8. Fujita, K. Development and Application of New Iridium Catalysts for Efficient Dehydrogenative Reactions of Organic Molecules. Bull. Chem. Soc. Jpn. 2019, 92, 344-351. [CrossRef]

(C) 2019 by the author. Licensee MDPI, Basel, Switzerland. This article is an open access article distributed under the terms and conditions of the Creative Commons Attribution (CC BY) license (http://creativecommons.org/licenses/by/4.0/). 